\title{
Development of remote identification the enterprises by digital technologies
}

\author{
Olena Sova ${ }^{1 *}$, Tetiana Ganushchak ${ }^{2}$, Valentyna Khrapkina $^{3}$, and Oksana Onyshchenko ${ }^{4}$ \\ ${ }^{1}$ National University of Life and Environmental Sciences of Ukraine, 15 Heroiv Oborony St., 03041 \\ Kyiv, Ukraine \\ ${ }^{2}$ Kyiv National University of Trade and Economics, 19 Kyoto St., 02156 Kyiv, Ukraine \\ ${ }^{3}$ National University of "Kyiv-Mohyla Academy", 2 Skovorody St., 04070 Kyiv, Ukraine \\ ${ }^{4}$ Kremenchuk Mykhailo Ostrohradskyi National University, 20 Pershotravneva St., 39600 \\ Kremenchuk, Ukraine
}

\begin{abstract}
The article is devoted to the formulation of electronic remote identification of enterprises by digital technologies. The paper determines a practical aspect of using electronic remote identification between the bank and the organizations. The article emphasizes that BankID system has great social importance and wide practical application in Nordics and Ukraine. It is analyzed the level of Ukrainian enterprises' computerization in various industries. The shares of some industries in the structure of the Ukrainian's GDP with the construction of a trend line are given. Authors compare states of electronic identification in the northern countries and advantages of BankID systems. The recommendations for improvement electronic remote identification the enterprises by digital technologies are made. Keywords: digitalization of finances, finance, finance of enterprises, remote identification, digital technologies, BankID, banking.
\end{abstract}

\section{Introduction}

There are many interactions of enterprises with their customers. They are moving to the Internet through global digital transformation. Identity verification must be done remotely. Now banks, mobile operators, and other enterprises must enroll and authenticate their customers without ever meeting them face-to-face. They must do it in a way that is secure, convenient, and complies with regulations.

The global development of information technologies and their wide application in all spheres of the life requires the transformation of identification processes in accordance with modern conditions. That is, the certain services such as administrative and public are offered in electronic form.

The digital transformation has fueled interest in remote identity verification in some sectors and has sparked the creation of new use cases in others.

An electronic identification system is a platform that unites all providers of remote identification services (electronic digital signature, ID-passport, MobileID, BankID). It provides accessible and secure electronic and citizens authentication and identification

\footnotetext{
* Corresponding author: sovy@ukr.net
} 
businesses in a convenient and secure cyberspace. The digital signature and electronic identification services are two main products that accelerate the digital interaction between participants, for example, in the scope of public services, tax payment or signing legal contracts.

The digital identification increases the interaction between society and business, strengthens trust for different geographical regions. It helps individuals and companies increase efficiency with lower operating costs and be more digitalized. Unexpected longterm coronavirus quarantine may force to work banks and their customers on-line even bigger.

So, the development of digital infrastructure and digital economy are important in building an open information society in the country for order to achieve national priorities.

The purpose of the article is to research the role of Information and Communication Technology sector in the formation of GDP, and provide recommendations for improving the process of remote identification of enterprises using digital technologies.

\section{Literature review}

There are the preconditions to say that the global demand for digital services will continue to grow, primarily due to the influence of digital trends and strategies for "digitalization" of corporations, large and medium-sized businesses.

The scientists from many countries devoted scientific works to the digital technologies integration from all spheres of business for achieve economic and social goals, rather and with new quality.

Boško Mekinjić explored how increased competition, new legislation, and all the changes that camewith digitalization, will affect the banking sector in the upcoming period which includes blockchain networks, artificial intelligence, IoT, biometrics, cooperation of banks with FinTech companies, preparation of the platform and other services for the Generation Z [1].

I. Sytnyk, V. Holovina studied the directions of electronic interaction of citizens with the authorities, information priorities of visitors to government websites and logging systems [2]. J. Shamah explained the banks' role as identity service providers and introduces four architectures representative for National eID schemes. A circle of trust between banks, government and financial institutions is described, based on anti-money laundering (AML) and Know-Your-Customer (KYC) checks, which reduce and help quantify risk and maintain regulatory compliance [3].

The article by Y. Korobov discussed the main transformation processes in banking sector: globalization, concentration of capital, formation of a new model of banking and new banking culture. Underlined that the development of internet information services makes it possible to provide a high degree of independence and freedom for bank customers who have the opportunity to compare the products of different banks [4]. A. Mehdiabadi, M. Tabatabeinasab, C. Spulbar, A. Karbassi Yazdi, R. Birau in their paper examined a systematic review of fully integrated Banking 4.0 and the application of the technologies of Industry 4.0 [5].

Chen Zhuming, Li Yushan, Wu Yawen and Luo Junjun analyzed the strategies, organizations, HR systems, and product innovations adopted by two banks (Citibank and ICBC) in response to the impact of FinTech [6]. Stoiko O. emphasized that the implementation of innovative solutions may be applying BankID remote digital identification, which will make the domestic financial market more accessible and open for its participants, simplify the procedure for rendering services and provide conditions for creating innovative services and improving the existing ones [7]. 
Regarding measures to manage the innovative development of the banking services market of Ukraine, we can note the following papers. Changes in the model of interaction between bank and client in Ukraine are characterized by A. Hulei [8]. A. Kyselov [9] established directions of state regulation of innovation development of the banking system of Ukraine.

Per Jonny Nesse, Hanne Kristine Hallingby, Sigmund Akselsen, Arne Munch Ellingsen, Erlend Glück Evensen recommended including the fact that mobile payment services by taking a role as a trusted service manager, focus on establishing the ecosystem and contactless payment service together with partners in the bank sector [10].

These articles consider scopes to stimulate the development of "Industry 4.0" from the standpoint of the banking system, and further research requires the digital tools use effectiveness for the business sector.

\section{Material and methods}

The study is based on the review of literature, scientific articles and the legal acts of the Nordic countries and Ukraine related to the processes.

Research methods used: method of generalization of theoretical knowledge is used in order to form an authors' approach to the definition of terms; tabular method, analysis which were used to estimate indicator position of the shares of some industries in the structure of Ukraine's GDP; graphic method, which was used to depict the shares of some industries in the structure of Ukraine's GDP; methods of synthesis, deduction, induction, which were used to comparison of electronic identity schemes in some Nordic countries; exponential method when a trend line was constructed; the approximation method was used for the prediction equation.

The priority in methods using was defined by the particular tasks and goals.

\section{Results and discussion}

The digital reformation is occurring at every level in the banking industry during pandemic period. From new technology to new competition to heightened customer expectations, banks have become increasingly vulnerable. For banks globally, 2021 could be a pivotal year in accelerating the transformation into more strategically focused, technologically modern, and operationally agile institutions, so that its may remain dominant in a rapidly evolving ecosystem.

In 2016 came into force The European Union's Second Payment Services Directive (PSD2) [11], which allows banks and third-party service providers (TPP) to securely exchange financial information and services electronically and with the permission of customers. It means that banks will be able to share their data with third-party developers. The developers will be able to make their software products based on bank data. The BankID system is the first step towards building a banking digital ecosystem. BankID is an advanced identity verification technology, an online banking verification system.

The ability to perform remote authentication without physical presence simplifies the process of obtaining services for customers. It is becoming increasingly popular among the population and while minimizing physical contact especially during a pandemic.

Advantages of BankID:

1. Convenience of verification and transmission of identification data - there is no need to re-enter the data, since they are already in the bank.

2. Security of storage and transmission of information - for customer service in the Internet banking system uses modern technologies for storing customer data. 
3. Saving time - no need to obtain an electronic digital signature (EDS) certificate, no need to stand in queues to receive documents.

The identification through BankID is no different from checking documents in banks when the customer is present. Identification using BankID for citizens differs from identification with an electronic digital signature by ease of use and popularity. The single digital signature is distributed among legal entities and each individual has a bank card. The BankID identification may have certain restrictions on the use of electronic services which depend on the bank that provides services with BankID.

The businesses use several financial solutions: at least one bank, an acquiring bank, an accounting / ERP platform, often a separate supplier of accounts / invoices, and accounts payable and / or acquisition decisions. More of these business solution providers allow you to make payments. Many of these suppliers are serving their own ecosystem of business buyers and their suppliers. Businesses need to manage their identification and access to their payment data through the ecosystem of their own suppliers. They must also control access to the counterparties' information with whom they exchange invoices and payments.

There are some good examples of digital identity schemes driving adoption in thirdparty services such as government, healthcare and payments. For example, in the Nordic countries, banking solutions dominatethe region, providing access to millions of users. Significantly ahead of other countries in the use of electronic identification schemes in Sweden, Norway, Finland and Denmark.

Widely considered that in Sweden, Norway, Finland and Denmark have some of the most balanced and socially conscious systems of government in the world. Let's compare theirs electronic identity systems (Table 1).

Norway, Sweden and Finland mostly rely on a multitude of commercial eID providers accepted by the government. In Denmark the market of trust services and their alternatives is dominated by the NemID scheme supplied by Nets DanID A/S. The scheme is supervised by the Ministry of Finance.

Table 1. Comparison of electronic identity schemes in some Nordic countries

\begin{tabular}{|c|c|c|c|c|c|c|c|}
\hline \multirow[b]{2}{*}{ Country } & \multirow{2}{*}{$\begin{array}{c}\text { Start } \\
\text { using } \\
\text { e-ID } \\
\text { systems }\end{array}$} & \multirow{2}{*}{$\begin{array}{c}\text { Level of } \\
\text { BankID's } \\
\text { penetration as } \\
\text { of the beginning } \\
\text { of } 2020, \%\end{array}$} & \multicolumn{2}{|c|}{$\begin{array}{c}\text { Number of users } \\
\text { as of } 2020\end{array}$} & \multirow{2}{*}{$\begin{array}{c}\text { Number of } \\
\text { authentications } \\
\text { per day, million }\end{array}$} & \multicolumn{2}{|c|}{$\begin{array}{l}\text { Percent of the use } \\
\text { occurrences, } 2018\end{array}$} \\
\hline & & & million & $\begin{array}{l}\% \text { of the } \\
\text { population }\end{array}$ & & $\begin{array}{l}\text { private } \\
\text { sector }\end{array}$ & $\begin{array}{l}\text { public } \\
\text { sector }\end{array}$ \\
\hline Sweden & 2004 & 78 & 8.5 & 83 & $*$ & 93.5 & 6.5 \\
\hline Norway & 2005 & 74 & 3.7 & 68 & 1.4 & 95.0 & 5.0 \\
\hline Finland & 2009 & 87 & 3.1 & 57 & 0.8 & 91.6 & 8.4 \\
\hline Denmark & 2010 & 85 & 4.6 & 80 & 1.9 & 91.0 & 9.0 \\
\hline
\end{tabular}

* No data

Source: created on the base [3; 12-15]

If we compare the countries by population, Sweden has an indicator twice as large as in any other country in the region. And it has the higher number of users as of 2020. But the level of BankID's penetration is the highest in Finland $-87 \%$. While the country has the lowest share of numbers of BankID users in total population (57\%). Denmark leads in terms of number of authentications -1.9 million per day.

Norway's BankID scheme grew more slowly than Sweden's and Denmark's, but it has still reached a high level of authentications.

The Finnish Online Bank Identification (TUPAS) eID came to an end on September 30, 2019. This platform no longer qualifies as a strong authentication method. The banks that own and administer the TUPAS technical protocol need to use others to provide electronic identitcations. For many users, the shift may even go unnoticed. Based on the legal framework provided by the eIDAS regulations, the Finnish government has established the Finnish Trust Network (FTN). 
Let's look at the dynamics of BankID-users in Nordics by account type (Fig. 1).

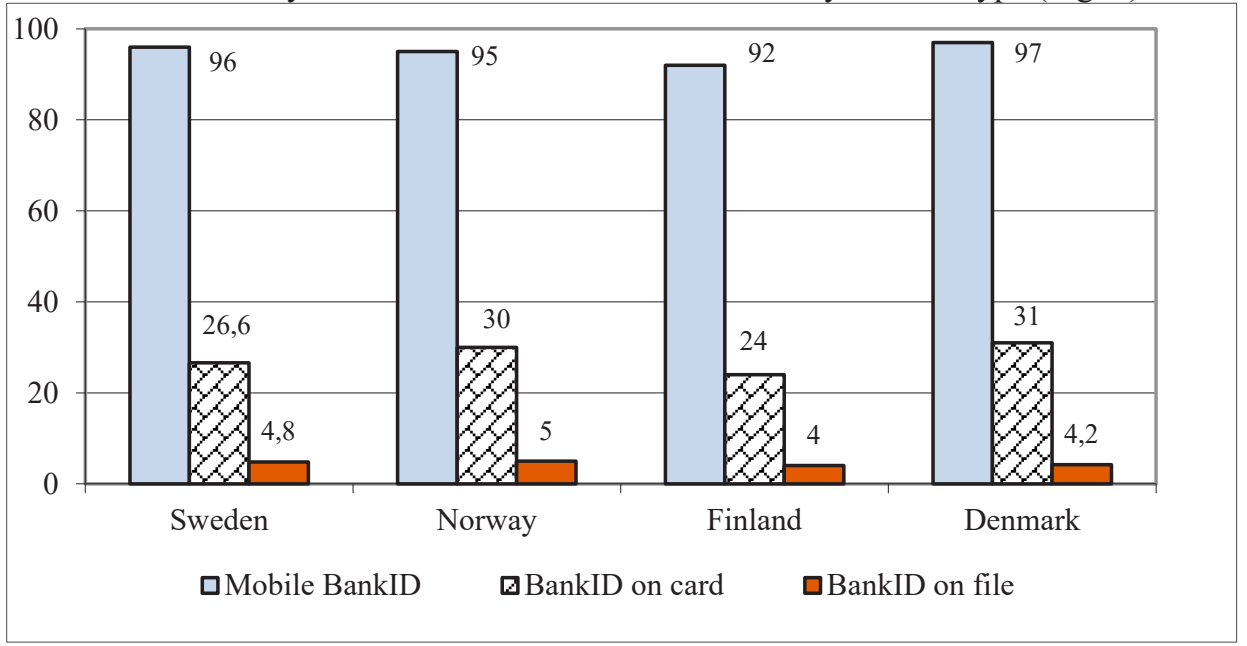

Fig. 1. Share of BankID-users in Nordics 2020, \%, by account type

Source: created on the data from [12]

According to Fig. 1, Sweden, Norway, Finland, and Denmark had Mobile BankID, BankID on card, BankID on file in 2020. The most used was Mobile BankID at all these countries. The first place is occupied by Denmark the level of digitalization in this period.

Another interesting point is what all four Nordic countries have in common. Key to all these schemes is the involvement of banks. Few other national organizations routinely verify new and existing users' identities, which makes banking the obvious place to start when building a national ID system.

But the Swiss have abandoned digital identification due to concerns about data security. Switzerland does not have certified state methods of verifying the digital identity of the country's population.

The legal basis for the introduction and development of electronic services in Ukraine is the Concept for the electronic services development in Ukraine for 2016-2020 [16]. This document laid down the state's principles policy in this scope and provides an appropriate set of measures for its implementation.

One of the main conditions for obtaining an electronic administrative service is the authorization of a person on the site in accordance with the analysis of the state's work web portals on the provision of electronic services.

So, the means of electronic identification - is a necessary condition for accessing and receiving public electronic services. Its special feature is the constant technical improvement and invention of new electronic identification types. It must be affordable and reliable.

The Law of Ukraine "On Electronic Trust Services" was adopted in 2017. It regulates relations in the scopes of electronic trust services and electronic identification [17].

The National Bank of Ukraine (NBU) began implementing the BankID NBU project in 2015. The Regulation on the BankID System of the National Bank of Ukraine was updated in the spring of 2020 [18]. A new stage in the development of the NBU's BankID began in July 2020 - the system's commercial model was launched.

The participants of the NBU's BankID system began to receive a fee for providing identification of their clients to commercial institutions participating in the BankID system of the NBU. This project' start was timed to the "split": from the 1st of July, the NBU became a regulator for insurance, leasing, financial companies, credit unions, pawnshops. It 
can use bank customer databases to identify new customers online. The connection remained free to the BankID system for Ukrainian banks, government agencies and commercial enterprises. The commercial model of using BankID provides a fee of about $\$ 1$ for information about each subscriber, and for the first two months of the using program, banks earned $\$ 35780$. Administrative and public services will not be charged. The system services remain free for users.

Today, the banks connected to the National Bank' BankID systemtogether account for $99 \%$ of the payment card market. Total, for the 1th of April in 2021 the BankID system has 84 participants [19]: 31 subscribed bank-identifiers, 43 commercial subscribed service providers, and 10 noncommercial subscribed service providers.

There are two BankID systems operate in Ukraine at once: from the NBU (the receiver of the Oschadbank system) and from PrivatBank. It is creates inconveniences for Ukrainian business entities. The National Bank added its own name to the title, for the average person this has little changed. The country's two largest retail banks, Privatbank and Oschadbank, are connected to two competing BankID systems. These banks have information on most of all bank customers.

Other banks are forced to choose which system to connect to or consider both options. The BankID system performs one function - it confirms that the user who provides the service is exactly who is he, and distinguishes between two systems, which are included only in the number of available services.

There is no model for calculating of the information and communication technologies' economic impact on certain industries and spheres of life in Ukraine. The current system of digital statistics applies only to the imported machinery and equipment number and the volume of IT services exports. There is no also official data on the coverage of the country's territory by digital infrastructures and the level of relevant services consumption.

Let's look into a scheme that illustrates the potential for growth in digital output in GDP (Fig. 2).

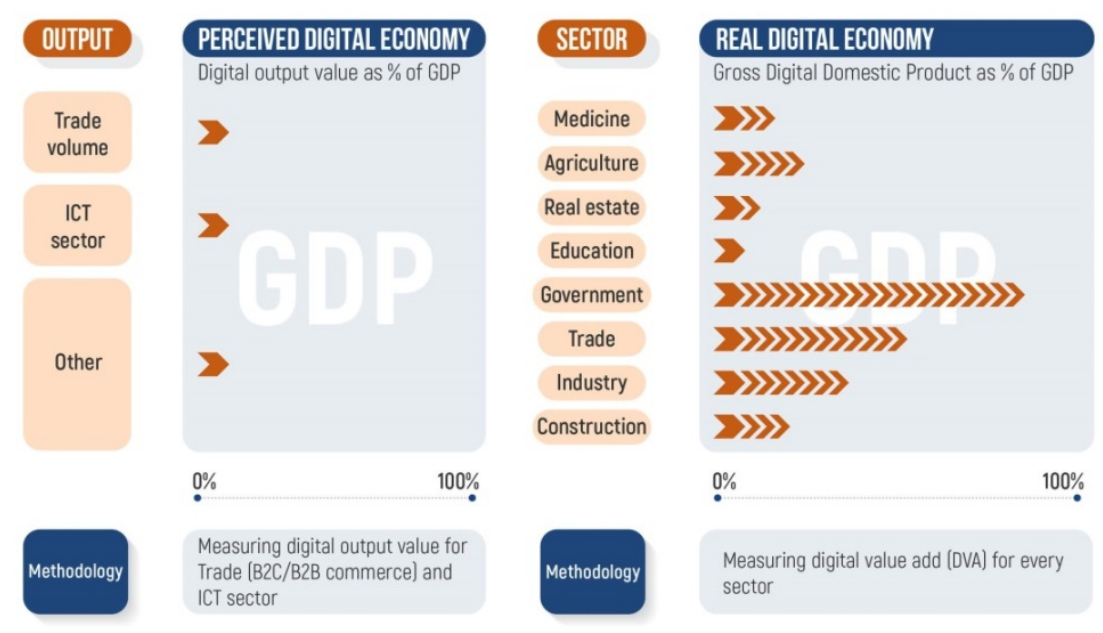

Fig. 2. Digital economy in GDP

Source: [20]

The ratio of the number of enterprises that used computers to the total number of enterprises by industry in Ukraine in 2020 is presented in Fig. 3. We can see that in 2020 the largest number of companies that used computers to the total number of companies was in the manufacturing industry, namely $25 \%$. The lowest indicator for the same period is reflected in the scope of Accommodation and food service activities, $1 \%$. 


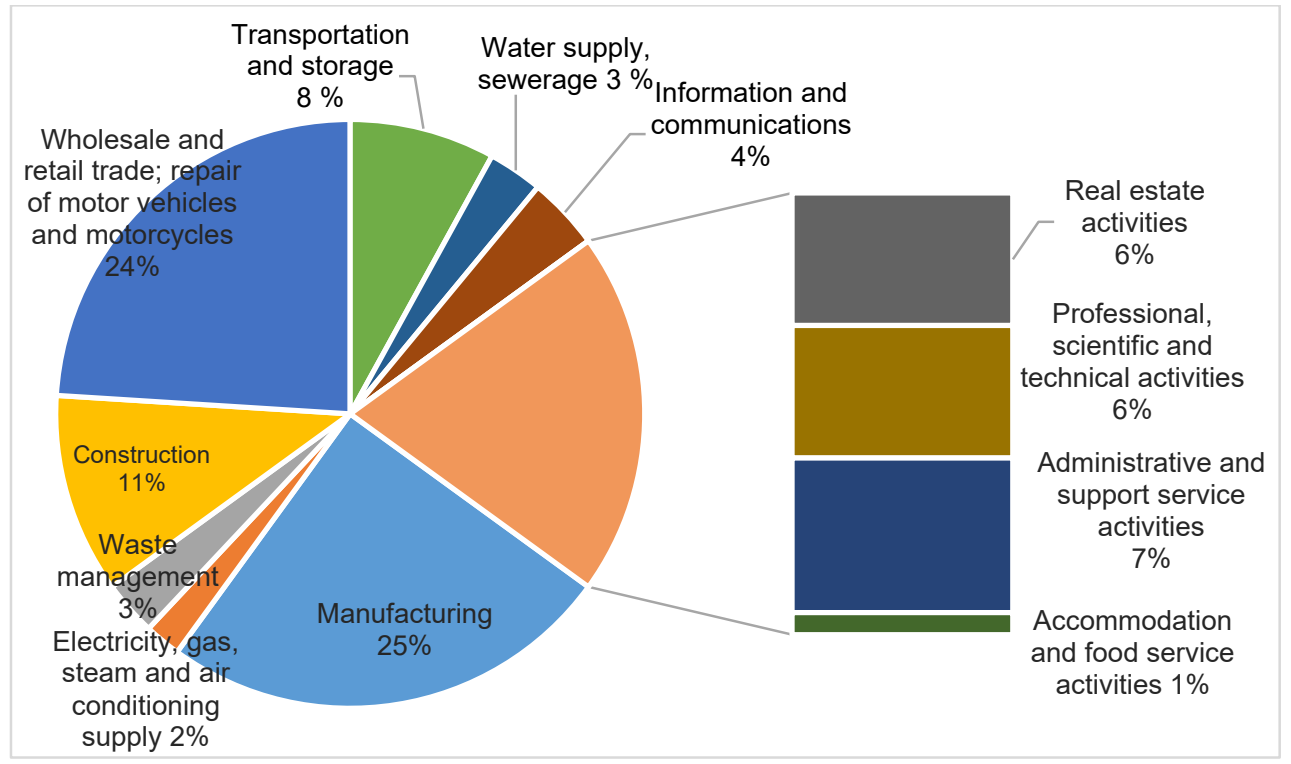

Fig. 3. The level of computerization of Ukrainian enterprises in various industries in $2020, \%$ Source: created on the [23]

The ratio of the number of enterprises that used computers to the total number of enterprises by industry in Ukraine in 2020 shows the leader - Manufacturing (25\%). Among the sectoral components of GDP value formation, we are interested in Information and communication technology (ICT). In Table 2 we will compare the shares of these two industries in the structure of the Ukrainian's GDP for the last five years.

Table 2. The shares of some industries in the structure of the Ukrainian's GDP

\begin{tabular}{|c|c|c|c|c|c|}
\hline Indicators & $\mathbf{2 0 1 6}$ & $\mathbf{2 0 1 7}$ & $\mathbf{2 0 1 8}$ & $\mathbf{2 0 1 9}$ & $\mathbf{2 0 2 0}$ \\
\hline $\begin{array}{c}\text { Gross domestic product, million dollars } \\
\text { including: }\end{array}$ & 87730 & 106339 & 128634 & 168007 & 148359 \\
\hline $\begin{array}{c}\text { Information and communication } \\
\text { technology, million dollars }\end{array}$ & 3283 & 3931 & 5015 & 7714 & 7373 \\
\hline in \% to the GDP, \% & 3.7 & 3.7 & 3.9 & 4.6 & 5.0 \\
\hline Manufacturing, million dollars & 10720 & 12825 & 14865 & 18168 & 15036 \\
\hline in \% to the GDP, \% & 12.2 & 12.1 & 11.6 & 10.8 & 10.1 \\
\hline
\end{tabular}

Source: created on the [23]

As we can see, the share of ICT sector is growing during the analyzed period: from $3.7 \%$ to $5.0 \%$. But Manufacturing's share in the structure of the Ukrainian's GDP is constantly declining - to $10 \%$.

The eID market in Europe is in a really dynamic phase, and as it continues to grow and evolve, Ukrainian ICT sector too is adapting to changing laws and technical standards to keep our clients up to date and in compliance.

In absolute terms the ICT contributes to GDP 7.4 billion dollars in 2020. This is 314 million less than in 2019. The share did not decrease because of reduction the nominal GDP in 2020 , GDP decreased by $11.8 \%$. 


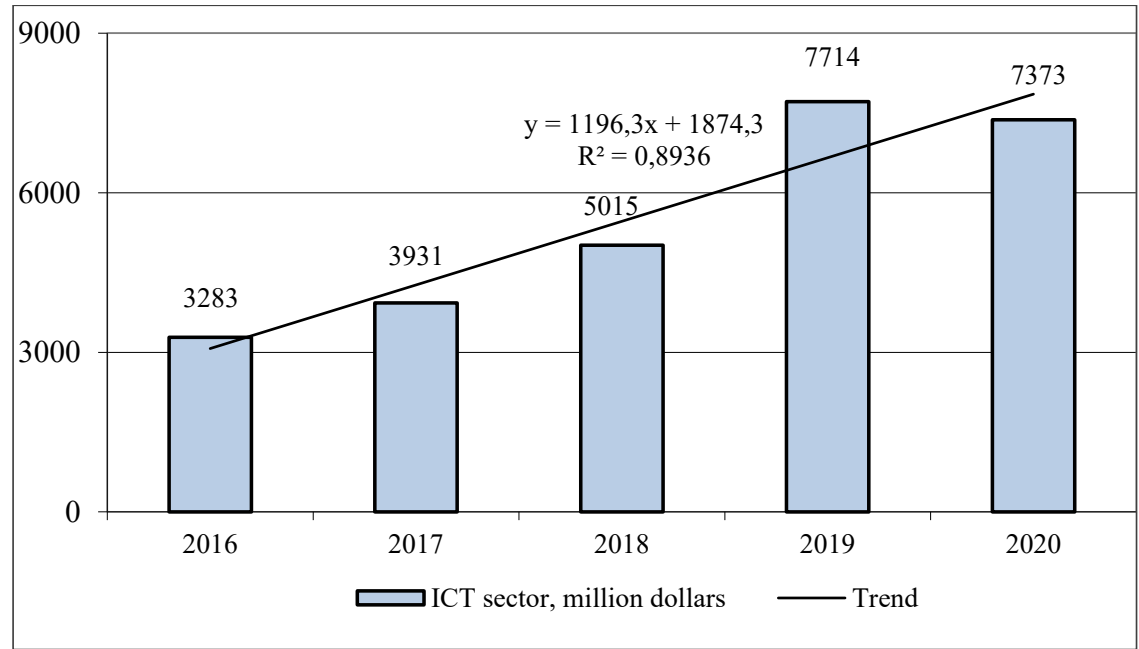

Fig. 4. The shares of Information and communication in the structure of the Ukrainian's GDP Source: created on the [23]

According to Fig. 4, it is seen that Information and communication in the Gross domestic product in 2016 as to compare with the year 2020 tended to grow increased. Let's see the dynamics. The trend line is a geometric representation of the average values of the analyzed indicators, obtained using any mathematical function. $\mathrm{R}^{2}-$ the value of the approximation's reliability shows the degree of the trend model's compliance with the original data. Its value is 0.8936 , which is close to 1 . The value of $\mathrm{R}^{2}$ shows that the model describes the data with high accuracy.

\section{Conclusions}

The wider adoption of digital identity schemes could present a drastic, positive change in the way in which customers interact with online services and gives banks and financial institutions the opportunity to be a driving force for this change. Fundamentally, the core business of financial institutions has been focused on enabling secure transactions with users who can verify their identity, which makes them the perfect providers of multipurpose digital identity frameworks.

Summarizing the results of the study of electronic remote identification of enterprises by digital technologies, we can draw the following conclusions.

The BankID system has great social importance and wide practical application. It allows you not depend on the location and schedule of government, commercial and public institutions. At the same time, it has security's high level, as personal information is transmitted in encrypted format through secure communication channels.

The economic crisis has weakened the activities of banks, but the use of the Internet and information technology opens up new opportunities for banks to quickly obtain information. The most people focus on the negative during a pandemic period.

Mainly from March 2020 enterprises all over the world stopped their activity, employees were left without work or were proposed to work remote. In general, the restrictions all over the world affected about a third of the world's population [22].

But there are also many positive moments. One such positive is the use BankID, which has reduced bureaucratization in many countries around the world. The software product BankID will allow switching to electronic control. The working with this software product will increase the liquidity of assets, profitability of banks and enterprises. 
There are following main aspects, the implementation of which will improve the data protection mechanism:

1) electronic providers of identification services must implement a set of organizational and technical measures to protect personal data and provide security guarantees appropriate level against risks of loss, destruction, leakage's prevention, information destruction and blocking;

2) personal and identification data must be used exclusively for the purpose specified in the notification on the purpose of data processing;

3) monitor compliance with legislation on personal data protection and information protection in information networks;

4) increase the information culture and security culture in the digital environment;

5) interact with participants in the electronic environment only through the provision of data that is necessary for a particular online transaction or receipt of an electronic service.

Today's transformation processes are a driving force in the development of innovation and strategic planning. Of course, enterprise's situational management with the use of the latest technologies is the development not only an individual enterprise, but also the whole of the country's economy. The important factor in economic's development is digitalization, which has penetrated into all spheres of the public life.

We will provide some recommendations for improvement electronic remote identification the enterprises by digital technologies. There are:

- increasing digitalization between banks and enterprises. This will reduce the number of mistakes that made by bank employees when serving customers;

- cooperating IT employees of the domestic banks with employees of different countries in this scope. It is necessary to improve the software products of banks in order to save time on servicing enterprises;

- developing a mechanism for managing the quality of service, product quality, operation of the bank's software products;

- creating refresher courses for banks managers for explanatory work to employees and of enterprises' top managers;

- increasing the level of an information and a financial literacy among the population that is an employee or future employee of enterprises;

- establishing relationships between banks, enterprises and universities to promote the financial literacy.

The authors would like to thank Kseniia Moroz, Senior specialist of Securities Department JSC Credit Europe Bank, for providing us with advices and directions on how to improve our article.

\section{References}

1. B. Mekinjić, J. Contemporary Economics, 1, 7-28 (2019)

2. I.P. Sytnyk, V.V. Holovina, Scientific Bulletin of Uzhhorod National University, 11, 145-148 (2017)

3. J. Shamah, The role of financial institutions in delivering identity-as-a-service for governments, Web Fraud Prevention and Online Authentication Market Guide 2017/2018, Thursday 8 March 2018 (2018)

4. Yu. Korobov, Global Banking: Transformation, Innovation \& Competition. Paper presented, in Proceedings of the SHS Web of Conferences. Innovative Economic Symposium 2017, 19 October 2017, (IES2017), Czech Republic, 39, 01012 (2017)

5. A. Mehdiabadi, M. Tabatabeinasab, C. Spulbar, A. Karbassi Yazdi, R. Birau, Int. J. Financial Stud., 8(2), 32 (2020) 
6. Ch. Zhuming, Li Yushan, Wu Yawen, Luo Junjun, Financ. Innov., 3,12 (2017)

7. O. Stoiko, The problems of economy, 2(44), 356-364 (2020)

8. A. Gulei, S. Gulei, Ukrainian J. Applied Econ., 4(1), 6-15 (2019)

9. A. Kyselov, Black Sea Econ. Stud., 36(1), 52-55 (2018),

10. Per J. Nesse, H. Kristine Hallingby, S. Akselsen, A. Munch Ellingsen, E. Glück Evensen, Int. J. Entrepreneurial Venturing. 9(1), 60 (2017)

11. EU European Payment Systems Directive (PSD2). https://eur-lex.europa.eu/legalcontent/EN/TXT/?uri=CELEX:32015L2366, [Accessed: 01 March 2021]

12. Statista Research Department, https://www.statista.com/markets/418/technologytelecommunications Accessed 01 March 2021

13. H. Hinsberg, K. Kaspar, L. Kask, A. Kütt, Study on NordicBaltic Trust Services, https://www.digdir.no/media/1063/download, [Accessed: 01 March 2021]

14. A. Bazarhanova, J. Yli-Huumo, K. Smolander, Electron Markets, 30, 525-538 (2020)

15. Banks have been the catalyst for Nordic digital identity success. https://www.finextra.com/newsarticle/33655/banks-have-been-the-catalyst-for-nordicdigital-identity-success, [Accessed: 01 March 2021]

16. Kontseptsiia rozvytku systemy elektronnykh posluh v Ukraini na 2016-2020 roky (The concept of development of the electronic services system in Ukraine for 2016-2020), https://zakon.rada.gov.ua/laws/show/918-2016-\%D1\%80\#Text [Accessed 10 March 2021]

17. Pro elektronni dovirchi posluhy. Zakon Ukrainy (On electronic trust services. Law of Ukraine), https://zakon.rada.gov.ua/laws/show/2155-19\#Text, [Accessed: 05 April 2021]

18. Polozhennia pro Systemu BankID Natsionalnoho banku Ukrainy: Postanova Pravlinnia Natsionalnoho banku Ukrainy vid 17.03.2020 No 32 https://zakon.rada.gov.ua/laws/show/v0032500-20\#n7, [Accessed: 05 April 2021]

19. Pro Systemu BankID Natsionalnoho banku, https://bank.gov.ua/en/bank-idnbu/abonents, [Accessed: 10 March 2021]

20. Ukraina 2030E - kraina z rozvynutoiu tsyfrovoiu ekonomikoiu, https://strategy.uifuture.org/kraina-z-rozvinutoyu-cifrovoyu-ekonomikoyu.html, [Accessed: 10 March 2021]

21. V. Hula, I. Storozhuk, Perevahy ta nedoliky vprovadzhennia systemy BankID v Ukraini, in Proceedings of the conferences of the Youth Scientific League, 19 June 2020, Ternopil, Ukraine, 70-71 (2020)

22. N. Bieliaieva, M. Krushelnytskyi, L. Voliak, N. Usata, O. Sova, Independent J. Manag. \& Production, 11(9), 2275-2290 (2020)

23. State Statistics Service of Ukraine, http://ukrstat.gov.ua/imf/arhiv/nr/nr2016_2020_u.htm Accessed 05 April 2021, [Accessed: 10 March 2021] 